of the arterial involvement secondary to a long standing venous congestion, actually representing a more advanced stage of the disease. Indeed, the presence of fibrous tissue within the gastric muscle coat is likely to represent the dystrophic effect due to the vascular abnormalities.

The acute ulcers and the superficial mucosal necrosis could be an expression of either alcohol dependent toxicity or ischaemic damage secondary to the prominent vascular alterations. Features in keeping with the latter pathogenesis are mucosal atrophy, submucosa fibrosis, and the presence of fibrous tissue within the gastric muscle.

In addition, we noted the similarity of some arterial abnormalities-intimal hyperplasia up to total lumen obliteration, diffuse duplication, and focal fragmentation of the internal lamina elastica - with the arterial anomalies described in primary angiodysplasia such as Dieulafoy's disease. ${ }^{10}$ Nevertheless, in the present case the clinical presentation in a cirrhotic patient with portal hypertension was not in keeping with the hypothesis of a Dieulafoy-like angiodysplasia that usually occurs in middle aged and elderly men without any relevant family history, excessive alcohol or aspirin intake. In addition, in Dieulafoy's disease the mucosal ulcer, localised in the upper stomach, is usually single, small, and shallow, whereas in our case the ulcers were multiple and deep penetrating. Finally, the prominent muscularisation of the veins was the main histological feature supporting a late stage congestive gastropathy rather than an angiodysplasia.

In conclusion, our study focuses on the large spectrum of microscopical vascular alterations present in a late stage congestive gastropathy, of which, to the best of our knowledge, this is the first description. The similarity with Dieulafoy-like angiodysplasia emphasises that clear cut criteria to define gastric vascular lesions do not exist yet.

1 Sarfeth IJ, Tarnawski A, Hajduczeck J, Stachura J, Bui HX. Gastric mucosal vasculopathy in portal hypertension. Gastroenterology 1987;92:1129-31.

2 Sarin SK, Misra SP, Singal A, Thorat V, Broor SL. Congestive gastropathy in portal hypertension: variations in prevalence. $A m$ f Gastroenterol 1988;83:1235-9.

3 Quitero E, Pique JM, Bombi JA, Bordas JM, Sentis J,

Montserrat E, et al. Gastric mucosal vascular ectasias causMontserrat $\mathrm{E}$, et al. Gastric mucosal vascular ectasias causing

4 Triger DR, Hosking SW. The gastric mucosa in porta hypertension. F Hepathol 1989;8:267-72.

5 Moore JD, Thompson NW, Appelman HD, Foley D. Arteriovenous malformations of the gastrointestinal tract. Arch Surg 1976;11:381-9.

6 Lewi HJE, Gledhill T, Gilmour HM, Buist TAS. Arteriovenous malformations of the intestine. Surg Gynecol Obstet 1979;149:712-16.

7 Fowler DL, Fortin D, Wood WG, Pinkerton JAJr, Koontz PG Jr. Intestinal malformations. Surgery 1979;86:377-85.

8 Scully R, Mark EJ, Mc Neely WF. Case records of the Massachussets General Hospital. N Engl F Med 1991;10:108696.

9 Tivadar L M, Vilmos AT. The caliber persistent artery of the stomach: a unifying approach to gastric aneurysm, Dieulafoy's lesion, and submucosal arterial malformation. Hum Pathol 1988;19:914-21.

10 Leone O, Zanelli M, Santini D, Minni F, Marrano D. Dieulafoy's disease associated with early gastric cancer. $\mathcal{f}$ Clin Pathol 1995;48:267-70.
Department of Pathology, State Laboratory, RIPAS Hospital, BSB, Darussalam, Brunei G Kafeel

P U Telesinghe

Correspondence to: Dr G Kafeel.

\title{
Inflammatory pseudotumour of the liver
}

\author{
G Kafeel, P U Telesinghe
}

\begin{abstract}
Inflammatory pseudotumour is not a common lesion. The first series of 12 cases was described in 1986, to which 37 more cases have now been added. The histology, differential diagnosis, and prognosis of this lesion have been described in detail, but the aetiology is unknown and the mode of treatment remains controversial. A new case is presented and compared with the previously reported cases. Fine needle aspirate yielded a growth of klebsiella organisms. The possibility of this infection as an aetiological agent is considered. (F Clin Pathol 1997;50:352-353)
\end{abstract}

Keywords: inflammatory pseudotumour; liver; klebsiella

\section{Case report}

A 70 year old female was referred to RIPAS Hospital, Brunei with a history of intermittent low grade fever, progressive weight loss and weakness, and vague abdominal pain on the right side. She looked sick and weighed only 32 $\mathrm{kg}$. Her body temperature was raised at $38.4^{\circ} \mathrm{C}$. A tender mass was felt in right iliac fossa. Ultrasonography of the abdomen showed a necrotic mass of $4.0 \mathrm{~cm}$ diameter on the inferolateral aspect of the right lobe of the liver displacing the hepatic flexure downwards. Except for a raised erythrocyte sedimentation rate (ESR) of $30 \mathrm{~mm}$ in the first hour the rest of her haematological and biochemical profile, including the liver function tests, was within the normal range. $\alpha$-Fetoprotein (AFP) and carcinoembryonic antigen (CEA) were not raised.

Ultrasound guided fine needle aspiration of the mass yielded about $2 \mathrm{ml}$ of turbid fluid which showed abundant neutrophils, fibrin and few degenerating liver cells on a necrotic background. No malignant cells, fungal elements, parasites, or acid-fast bacilli could be seen. Klebsiella spp were cultured from the aspirated material. The lesion was considered to be inflammatory. After six weeks of treat- 


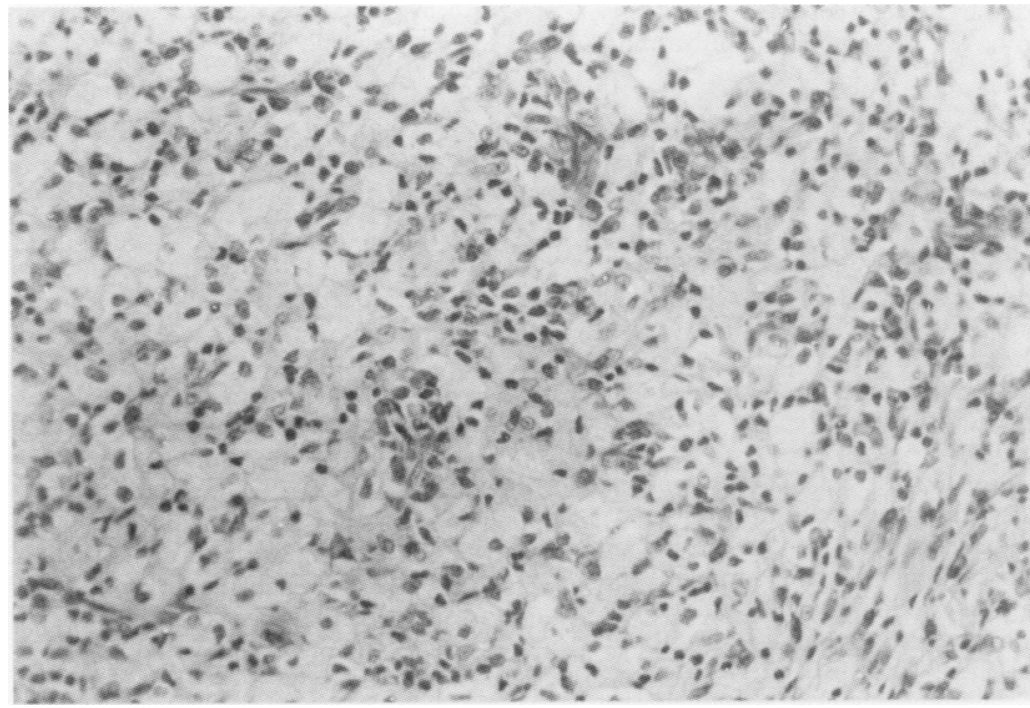

Figure 1 Plasma cells and lymphocytes mixed with prominent aggregates of foamy histiocytes (haematoxylin and eosin stain, $\times 31$ ).

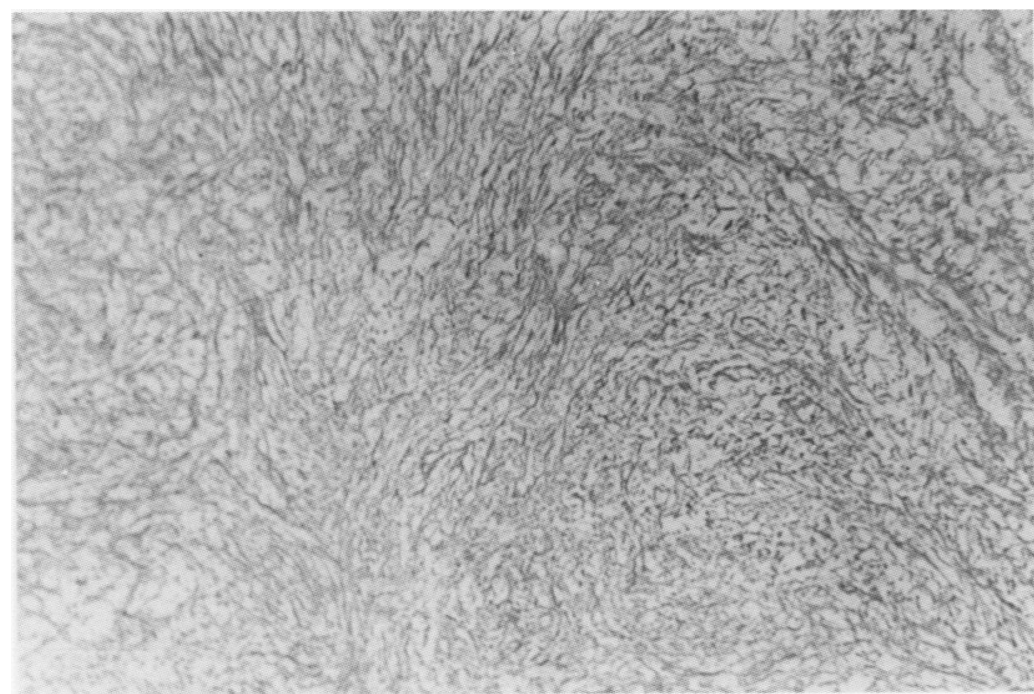

Figure 2 Proliferating fibrous tissue arranged in a whorled pattern (Gordon and Sweet reticulin stain, $\times 31$ ). granulomas were seen. No organisms were seen on Gram stain. Stains for fungus were non-contributory. The portal tracts in the adjacent liver showed fibrosis and chronic inflammation.

\section{Discussion}

Inflammatory pseudotumour is a rare lesion, occurring at all ages. ${ }^{12}$ As the name implies, is a lesion of inflammatory histology which commonly masquerades as a tumour. The usual presenting features are low grade fever, weight loss, hepatomegaly, jaundice, and leucocytosis. The histology is of a well capsulated mass of proliferating fibrous tissue arranged in whorls. The inflammatory cell component is rich in polyclonal plasma cells, lymphocytes, and histiocytes. CEA and AFP are never raised. ${ }^{1}$ There is controversy about the pathogenesis of the disease. ${ }^{134}$ Some regard it as an abnormal exuberant tissue response to some external stimulus. ${ }^{4}$ Others think that it is a sclerosing lesion similar to retroperitoneal fibrosis.

The present case satisfied most of the above diagnostic criteria of an inflammatory pseudotumour, though leucocytosis and jaundice were absent and the ESR was only minimally raised. However, the important feature was the isolation of klebsiella organisms on smear and culture. There have only been a few reports where organisms have been found ${ }^{4}$ and the presence of infection is usually considered to be incidental, ${ }^{1}$ though Lupovitch et $a l^{4}$ found Gram positive organisms in smears from the lesion, suggesting the possibility of a streptococcal infection which finally organised into the pseudotumour. Because of early detection and regular follow up in our patient, the gradual evolution of an inflammatory pseudotumour from an abscess caused by klebsiella was clearly demonstrated. The organisms were not seen in the resected mass, possibly because of the antibiotic treatment. Since the pseudotumour was resected after a relatively short period, the histology showed prominent aggregates of foamy histiocytes.

Our case supports the view that inflammatory pseudotumour arises from a low grade infection which organises early and may not be detectable at the time of presentation. Inflammatory pseudotumour should always be considered in the differential diagnosis of a mass in the liver with normal CEA and AFP levels. A needle aspiration or biopsy should be done to avoid major hepatic surgery.

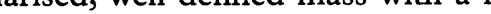
capsule. The mass was composed of oval or spindle shaped cells with vesicular nuclei and prominent nucleoli, cells with foamy cytoplasm (fig 1), multinucleated giant cells, and whorls of fibrous tissue (fig 2). The inflammatory cell component consisted mainly of plasma cells with an admixture of lymphocytes. Plasma cells were polyclonal in nature, secreting mainly IgG and both $\kappa$ and $\lambda$ light chains. All the other cells reacted positive to histiocytic markers (lysozyme, $\alpha_{1}$-antitrypsin). No endophlebitis or

\footnotetext{
Anthony PP, Telesinghe PU. Inflammatory pseudotumour of the liver. F Clin Pathol 1986;39:761-8.

2 Brunello F, Caremani M, Marcarino C, Benci A, Menchetti $D$, Emanuelli $G$. Inflammatory pseudotumour of the liver: diagnosis by fine needle biopsy in two cases and a review of literature. Ital $\mathcal{F}$ Gastroenterol 1994;26:151-3.

3 Pokorny CS, Painter DM, Waugh RC. Inflammatory pseudotumour of the liver causing biliary obstruction. $\mathcal{f}$ Clin Gastroenterol 1991;13:338-41.

4 Lupovitch A, Chen R, Mishra S. Inflammatory pseudotumour of the liver. Report of the fine needle aspiration cytologic findings in a case initially misdiagnosed as malignant. Acta Cytol 1989;33:259-62.
} 